\title{
Warehouse Processes Improvement by Pick by Voice Technology
}

\author{
Nikola DUJMEŠIĆ, Ivona BAJOR, Tomislav ROŽIĆ
}

\begin{abstract}
Research related to performance evaluation implicates defining work efficiency as result of substituting classic RF by pick by voice technology in warehouse infrastructure. The research outlined the benefits and effect of implementation in comparison with RF order picking. The comparison has been made from the aspect of workers productivity in the warehouse, the accuracy of goods collection and time required for workers training. Based on recent research on the Croatian logistics market, $\mathrm{RF}$ technology is mostly used as a given, manual picking is solution for majority of companies. Pick by voice technology is rarely used, by few manufacturer's warehouses and retailers with the highest share on the Croatian market, although companies are announcing its implementation. Although it results in certain benefits, the implementation of a pick by voice system generates large initial costs.
\end{abstract}

Keywords: order picking; pick by voice; RF system; warehouse operations

\section{INTRODUCTION}

Fast growing industry influenced retailers and warehouse operators to continuously search for solutions that will increase efficiency and productivity of everyday warehouse operations, especially order picking.

Authors Grosse et al. used content analysis approach that included 98 referent papers on order picking planning models with focus on human factors. According to authors, the greatest impact that humans have on warehouse operation performance includes minimizing traveling distance, total costs and throughput time. [1] Nowadays, many production and logistic systems, including warehouses, are still based on manual activity, and therefore, also great impact on performances and costs deeply depend on human availability and productivity. [2]

Berger and Ludwig (2008) and Richards (2014) conducted research focused to outline pick by voice system capabilities and its influence regarding warehouse operations. The results and suggested improvement was mostly in favour of pick by voice technology. Papers proved that productivity and error rate have been improved in all the observed samples. Also, synonyms that can be found in literature for pick by voice technology are voice picking and voice-directed warehousing.

Vocollect conducted research with over 200 logistics executives regarding pick by voice technology, starting with the fact that supply chain subjects are focusing to process higher volumes or a larger number of unique products with the same provided resources. Omni-channel results in increased number of received orders, which increases the workload, thus obliging the picker to collect more lines. Such development phenomenon in warehouses with standard RF (Radio Frequency) technologies increases the chance of lapse. The requirements imposed on experts can be generally obtained by implementing pick by voice technology. Pick by voice technology enables the synchronization of the flow of products and maximization of efficiency throughout the DC (Distribution Centre), minimizing resources and raising picking accuracy. [3]

Commonly, pick by voice technology addresses the key business problems with high investment costs. By not demanding the interfacing with WMS (Warehouse Management System) it finds the purpose in mid-sized warehouses with the possibility to impact other processes, not only order picking. [4]

Order picking optimization is often observed from different aspects focusing on warehouse layout, collection route, SKU (Stock Keeping Unit) location, order picking method, etc. Certain logistics companies on the Croatian market lately have implemented pick by voice technology with focus on optimizing order picking at warehouses, opening the possibility for measuring the level of optimization. While using pick by voice technology the warehouse operator has the benefit of being more focused on picking and being more accurate, easily following instructions. The influence of using this technology can also result in the reduction of return amounts, after all expecting certain reduction of total logistics costs. This paper has analyzed the effects of implementation of pick by voice system on warehouse processes at two Croatian market companies. The companies were willing to participate in the research, providing data before and after pick by voice system implementation. The companies highlighted the problems in everyday warehouse management, from the aspect of warehouse workers productivity, the accuracy of goods collection and the time required for workers training.

In the following sections, general warehouse processes and pick by voice technology system will be summarized. The performance evaluation provides a review of the existing process efficiency, while further statistical analysis of warehouse operations with implemented pick by voice technology highlights its impact on warehouse operations.

\section{ORDER PICKING PROCESS}

Logistic operations in warehouses strive for optimization, where seconds in activity can be a challenge to gain directly influencing the reduction of total process time. The total process time is not negligible considering the fact that because of disordered processes there are often additional operators included in the processes, with undefined normative and decreased productivity.

Authors Groose and Glock [1] refer to order picking as one of the most labour and time consuming processes in supply chains. The order picking process is defined as the process of retrieving items from storage locations in 
response to a specific customer request. Over the last decades, the researchers have developed various planning models that help increase the efficiency of order picking systems, while important, basic human characteristics of order pickers have generally been ignored. [1]

Order picking is not only one of the most labour and time consuming processes, but it also has direct impact on the service level. With a direct link to total operating costs that grew up to $55 \%$ and generating time consumption, it is very important to invest some efforts into reducing order picking costs and shortening the cycle time. Đukić et al. [5] claim that the key is to improve order picking efficiency and the time spent on travelling in warehouses, it can all be minimized with reducing routes and with improved planning of travelling distances. This finding is substantial for better understanding of the work, which is based on the claims of reducing the time using pick by voice technology.

According to Bartholdi and Hackman [6], warehouses reorganize and repackage SKUs where in accordance to orders, the outbound operations include manipulation of small handling units. In an environment where warehouse operators have more units to handle, the operations are more labour intensive. In general, the smaller the handling unit, the greater the handling cost.

Mendes [7] considers that various control problems deserve attention. First, the total pick area must be divided into picking zones, to be served by different order pickers, through a zoning policy. There are two alternative policies: parallel or sequential zoning, single order picking and batch picking.

Zhang [8] developed a CSAS (Correlated Storage Assignment) strategy in order to reduce the travel distance in the picker-to-parts order picking system. In the conducted study, the use of developed algorithm, compared with the full-turnover storage, reduces maximally $2.08 \%$ of the average travel distance per picking. [8]

Rakesh and Adil [9] based their research regarding warehouse layout and its effect on certain costs and storage capacity. A step toward warehouse optimization is the use of algorithm that determines the lane depth, the number of storage levels, lateral depth and longitudinal width of a three-dimensional order picking warehouse. It also helps in knowing the quantum of change in cost due to change in different parameters, which is difficult to predict due to the interaction of multiple effects and trade-offs. [9]

Order picking typically accounts for about 55\% of warehouse operating costs; and order picking itself may be further broken into travelling, searching, extracting and additional activities such as paperwork as shown in Tab. 1 . [10]

Table 1 Order picking time [10]

\begin{tabular}{|l|c|}
\hline \multicolumn{1}{|c|}{ Activity } & Order picking time (\%) \\
\hline Traveling & 55 \\
\hline Searching & 15 \\
\hline Extracting & 10 \\
\hline Paperwork and other activities & 20 \\
\hline
\end{tabular}

As Richards [11] mentioned, many of today's WMSs allocate product locations in advance and instruct the order picker where to position the SKUs. An order picker can be directed to a dispatch area, if the SKU is to be cross- docked, or directed to a reserved or bulk storage location for further forwarding.

Picking methods in warehouses vary in dependence of the number of items and warehouse workers. The manual method is generally still used in small warehouses with a small number of items. In practice this means that paper and pen are used to keep track of the work that is being done. The RF system method implies the use of Hand Held Terminals, further in the text HHD. HHDs are commonly used in most warehouses and they can offer high productivity and fewer mistakes. HHD implies a small computer that is used for receiving data from the central unit and for transmitting the collected information in the opposite direction via wireless transmission. It is equipped with a scanner to collect data. The spatial factors that constantly affect HHD usage are often low light and freezing conditions. Holding HHD in one's hand limits the operator's speed and draws focus away from the task.

Pick to light method is mostly used in specific types of warehouses and sorting areas. Pick by voice method is described more closely in the next chapter.

Pick lines are defined as instructions to order pickers, directing them to SKU locations and the amounts to pick. According to Bartholdi and Hackman [6], WMS organizes pick lines into pick lists to achieve efficiency, so that the order picker may be able to concentrate on one area of the warehouse to reduce traveling. The pick lists may be a physical sheet of paper, or a sequence of requests communicated by a stream of printed labels, RF, or pick by voice or light.

\section{PICK BY VOICE SYSTEM}

Since its emergence in the 1940s, voice technology has impacted a variety of industries. More worldwide companies are using voice systems to automate customer service, order placements, banking transactions and information dissemination. As this technology has a continuation in its growth, the companies are becoming increasingly aware of the benefits considering and accepting voice technology as potential for process optimization.

The voice technology has made significant inroads into labour intensive, industrial functions such as manufacturing and distribution, where the ability to be voice-directed is literally freeing up workers to be safer in the workplace, more accurate in their functions and more process focused. [3]

Picking methods in Fig. 1 summarize the possibilities and characteristics of each picking method and their impact on the productivity and accuracy of the given assignments.

Overall, the most important benefit of pick by voice technology is the guarantee of free hands and eyes. While employing seasonal workers, the number of training days has a great impact on selecting a proper picking method. A worker can switch from HHD to pick by voice in 1 to 2 days with no additional time spent on training. A picker can learn the basic commands and be ready for work in 15 minutes. All the devices are body-worn and the possibility of falling is minimized; there are no extra costs and no need for a great number of spare devices. 
According to the conducted research, voice-directed picking provides a certain level of efficiency, accuracy, while reducing errors to minimum.

Warehouse processes that can be affected by pick by voice are mostly replenishment, receiving, put away, while utilization is still possible in almost every warehouse process. Most companies see the greatest benefit in reducing the costs as shown in Fig. 2.

During implementation, it is useful to gather information to quantify the benefits that pick by voice will bring to the warehouse operations. The easiest way to evaluate is to set goals that will have impact on making the decision about implementation like simple comparison between a few parameters like system cost, cost per error, time saving, etc. The data points that affect the productivity calculation in the ROI (return on investment) analysis include: yearly total productive hours, average distributive centre burdened hourly wage, productivity improvement (\%).

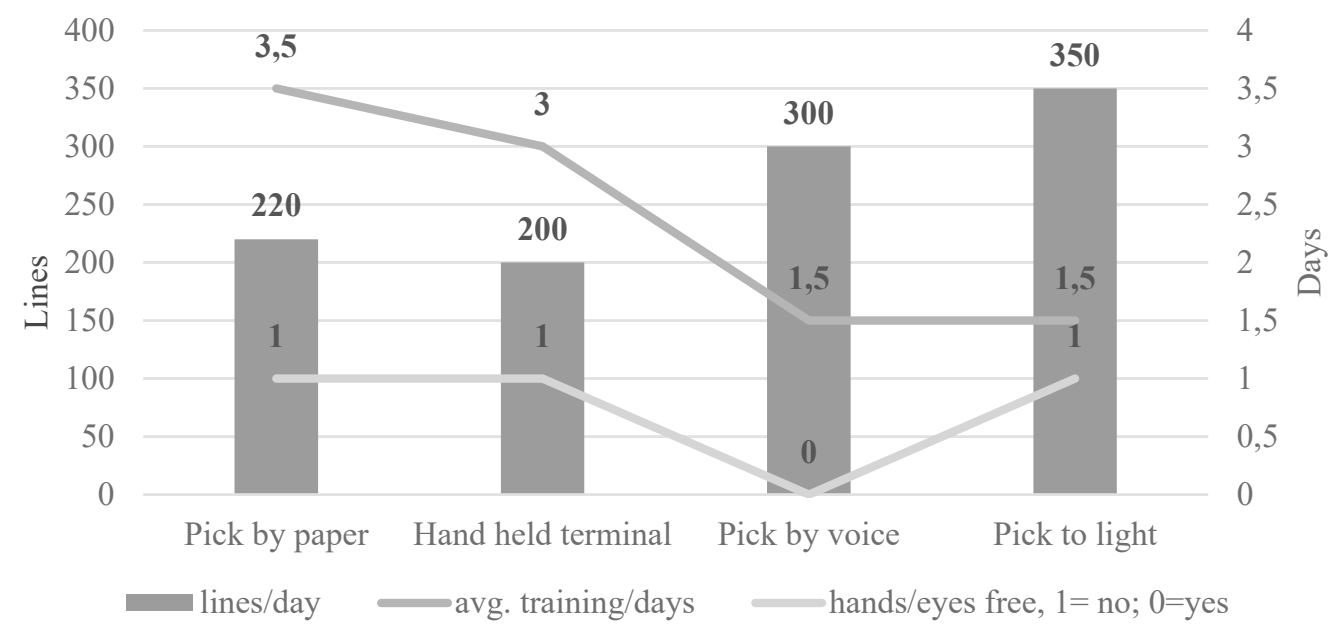

Figure 1 Case picking by various technologies [12]

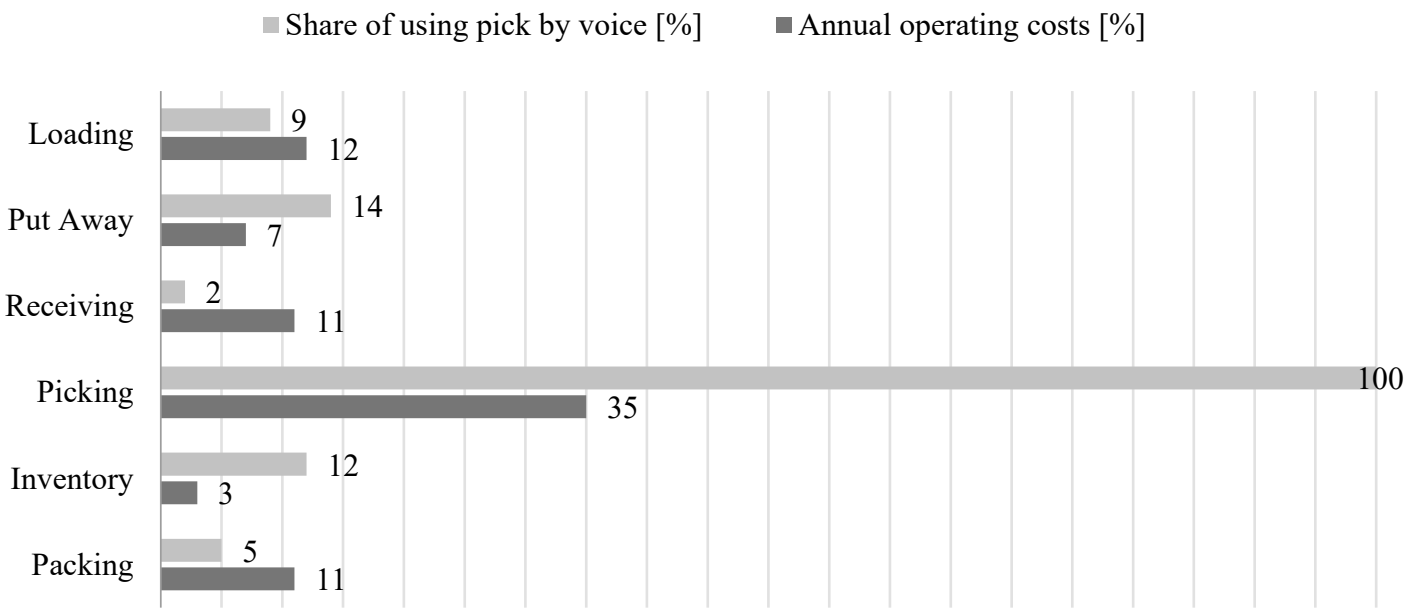

Figure 2 The share of using voice-directed technology and annual operating costs in warehouse processes [13, 11]

Pick by voice system is complementary with the existing WMS system or with ERP (Enterprise Resource Planning) in a form of an added value. The information from a host is transmitted over a wireless network and sent to a control unit worn around the operator's waist. The control unit receives radio waves (RF) and translates data into audio signals. The received assignments are generated into audible commands to the operator. After receiving a command, the operator speaks their respond to the control unit. Using simple communication, the operator confirms the taken actions and a pick by voice system responds with the next assignment. The response is translated to data and the host system is updated. [14]

Several benefits of pick by voice have been suggested by Borlakis, Clachos and Vasileios, 2011:
- Increased accuracy: The reduction in picking errors is one of the most important benefits of pick by voice despite the fact that the error is $0.5 \%$ of orders in conventional systems.

- Increased productivity: Pickers can focus their eyes on movement and their hands are free. The picker can focus on a product and in freezers the use of terminals is hampered.

- Cost reduction: Cost of printing and distributing the pick list is eliminated.

- Reduced training: Verbal prompts are easier to understand and the worker can learn easily all commands in a short period of time. [15] 


\section{RESEARCHED KEY WAREHOUSE PROCESSES IN CROATIAN COMPANIES}

Two companies that are the subject of this research are among the leading companies in their domain in the Republic of Croatia. Data were collected at two different warehouses before and after the implementation of pick by voice technology. The specifications of the subject are provided in the next chapter.

Regarding the picking criteria, all SKUs aimed at picking are placed on the level zero and level one. The

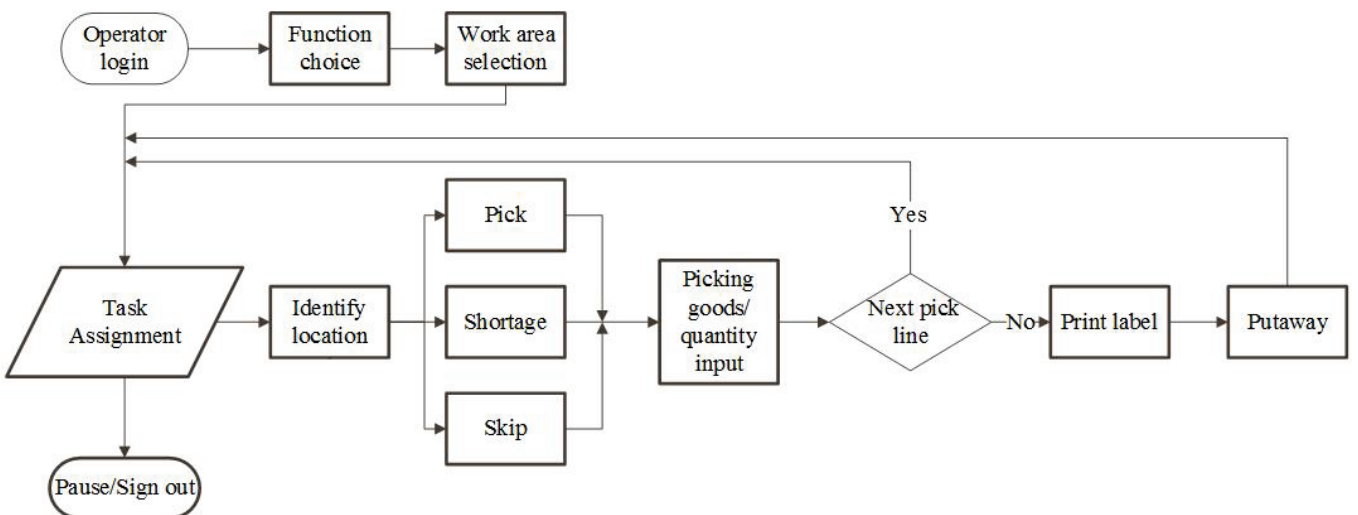

Figure 3 Picking process flow operators can pick pieces, boxes or whole pallets. Every operator picks one order.

Due to extremely low temperatures of the observed warehouses, the operators are additionally burdened, as well as the IT equipment, which was adapted to these conditions. Since operators wear gloves, the usage of HHD is not practical. The implementation of pick by voice as a fundament demands clearly defined processes as shown in Fig. 3.
When the operator receives an instruction, they search for a specific location confirming it using two options:

- bar code verification,

- control number assigned to every position.

Confirming a location with pick by voice system is performed by pronouncing the verification number. The operator receives information about item quantity and other instructions if there are any. In most cases, the verification of a location is performed within other work processes: arrival on location, moving forklift, manipulation of goods. Pick by voice systems analogously request the check of numbers, which have to be spoken by the picker.

\section{RESEARCH AND RESULTS}

The companies included in the research had various problems with managing their work resources and time in a proper way. The conventional methods used have proven to be effective, while additional processes improvement was partly impossible with the current picking technology. According to the management decision, HHDs were replaced by pick by voice technology.

The observed two warehouses were part of the research, providing data and processing according to the predefined criteria:

- picked size: package;

- warehouse type: high rack;

- warehouse area: 4,500-7,000 square meters;

travel path: serpentine;

- warehouse type: deep-freeze storage.

The companies included in the research are intensely seasonal, so therefore the number of workers varies from 20 up to 50. Previous analysis while implementing pick by voice technology had significant process improvement opportunities. On the average, 36 pickers worked per day and 8 warehouse workers had to provide control with $99.95 \%$ accuracy. In total, they had 6,000,000 pick assignments and 2,800 errors per year. Productivity remained on the average 130 lines per day. Since there is a great number of similar products, the training for a new operator took at least one working day. A long training period is not favourable in seasonal companies and it is just a needless cost. [13]

Measuring the difference between two technologies was provided by using the period per line. Time per line refers to the average time gain from the total time spent on performing of a single order.

\subsection{Warehouse Process with HHD}

Fig. 4 shows the average order picking times which are the result of research using HHD in warehouse processes and their comparison with the implementation of pick by voice technology. During previous research on the Croatian market, the average travel time and search time presented are typical also for other companies, satisfying the same pre-defined criteria. It is worth noting that significant time period is lost on searching due to the usage of HHD during the pick process hampering free movement. The pick time per line with HHD is not dependent on the number of lines in the order and refers to the time required to perform a pick of one line in task. The results are gathered within 300 tasks and 13 lines per task on the average, and the results are presented in Fig. 4 where the average travel time plus search time is $13.49 \mathrm{~s}$ and pick time is $12.35 \mathrm{~s}$. After the implementation, primarily a reduction of search time and a reduction of pressure on warehouse worker obligations are expected. Also, search and travel time can be minimized by optimizing the travel routes. 

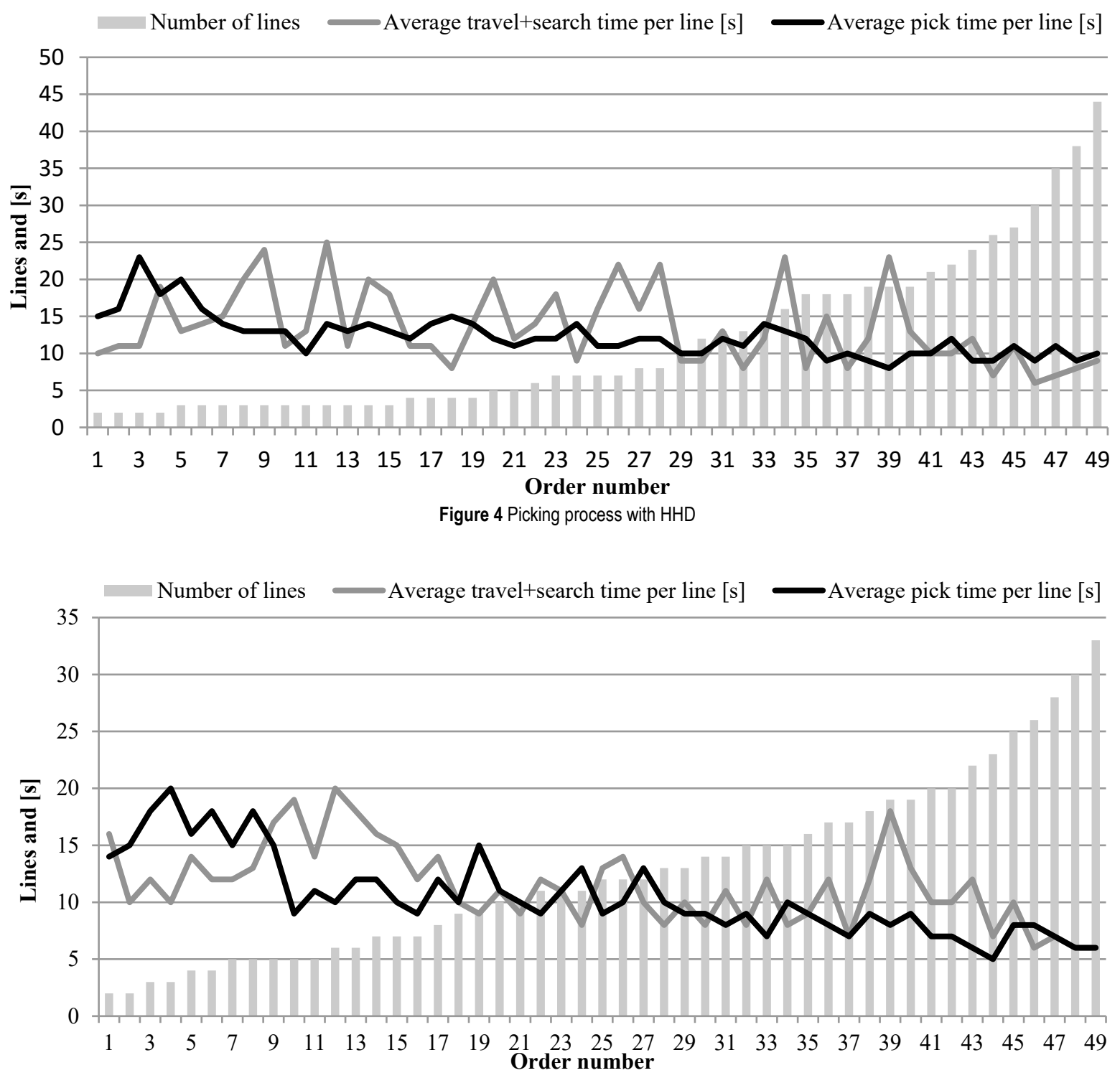

Figure 5 Picking process with pick by voice

\subsection{Warehouse Processes with Pick by Voice}

As a proof of improvement, in measurable segments such as picking and the search time is given, with processed data after implementing the pick by voice technology. Significant improvement is gained by reorganizing the warehouse processes and with simple instructions for warehouse workers order collection. Search and pick times with pick by voice technology are interdependent with the number of lines in an order. For instance, a higher number of lines means greater improvement. Search time is reduced due to the independency of HHD; precisely free eyes and hands means more focus on executing tasks which is shown in Fig. 5. Given results claim that search time plus travel time is $11.45 \mathrm{~s}$ on the average, and pick time is $10.55 \mathrm{~s}$ on the average. For comparison, the time difference after implementing pick by voice is 15 to $20 \%$ in favour of the pick by voice. When a warehouse is considered on a wider scale, then the rendered difference makes significant changes. After the implementation, the warehouse workers confirmed the user-friendly interface and reduced pressure due to hands free for collection.

\subsection{State Comparison Before and After Implementation}

Comparing the results before and after the implementation of pick by voice technology, an improvement of $20 \%$ has been noted on the average when changing from HHD to pick by voice technology under the observed data.

A significant boost in productivity and in decreasing costs is continuously visible. Implementing pick by voice technology led for the observed companies to a significant process improvement. After the implementation, the workload has significantly increased and the assumed decrease of control point warehouse workers to zero is still not possible. Two control point warehouse workers are still involved in the warehouse processes.

When calculating the investment, the greatest savings are obtained by decreasing the number of employees. Productivity is increased by $70 \%$ and errors have been almost eliminated in the output process. On the average, pickers have 170 lines per hour and the fastest ones have 200 lines per hour and more. Pick by voice technology has a significant increase in productivity with increasing the 
number of picking lines. For example, productivity and improvement are greater when 15 lines are picked rather than 2 to 5 as shown in Fig. 6. As mentioned in the description of the chart above, it is evident that pick by voice technology provides an additional advantage over conventional methods such as the use of HHD.

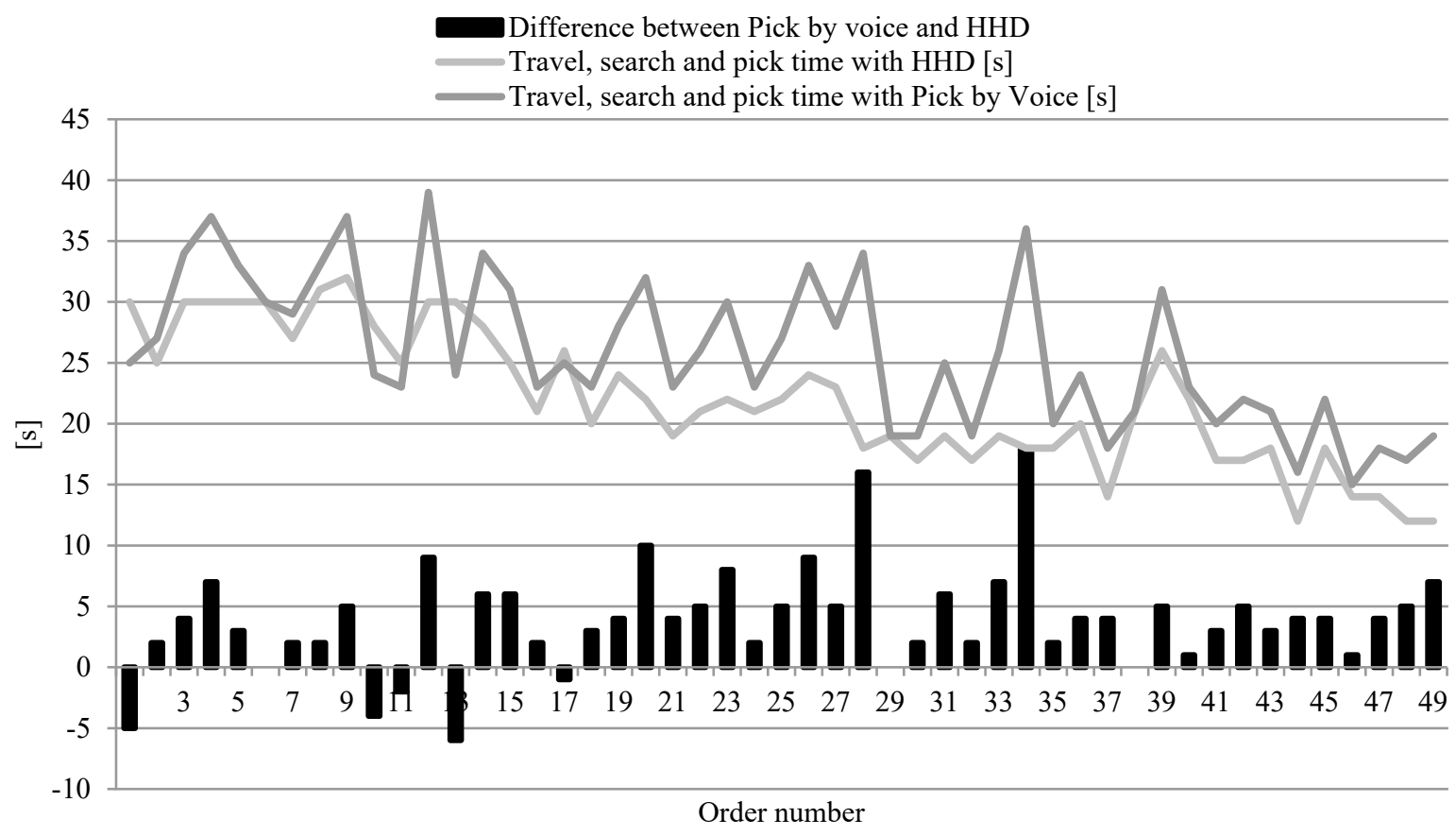

Figure 6 Productivity improvement

\section{CONCLUSION}

Order picking is the most often observed process for optimization with operation costs that can account for approximately 55\%; also order picking is a great indicator of warehouse productivity.

Pick by voice technology has found its purpose in different warehouse types regarding process design and type of goods stored. Mostly, the technology is used for picking while it can be used for improving other warehouse processes. Regarding picking, considered as a process with the highest share in overall warehouse costs, the implementation of pick by voice technology can provide significant savings. The savings can be made by minimizing or completely eliminating the control point during outbound process, accuracy and picking efficiency.

Although pick by voice technology clearly shows positive results, for the Croatian market it is considered as a highly expensive technology which is confirmed by a survey conducted on a sample of 100 subjects. More than $60 \%$ of respondents believe that pick by voice technology can contribute with many benefits. Only $20 \%$ of stakeholders consider investing in this technology as something that would contribute to further development of their companies.

Also, with pick by voice technology, the possibility of hiring seasonal workers is optimal since training for pickers lasts maximally one shift, although practice implicated that the warehouse workers can start to work independently in as little as two hours. With hands free, the work environment is defined as safer and the possibility of an accident is reduced.

Overall, the impact of implementing pick by voice technology in warehouse logistic processes is a solution that gives added value to the existing warehouse processes.
According to research and practice, pick by voice technology affected most warehouses that implemented technology by giving more efficient pick time.

According to the results of the conducted study, approximately $20 \%$ of process improvement has been gained and the number of control points in the first phase is minimized. Due to the higher number of orders after the implementation, two warehouse workers at one warehouse were allocated to control outgoing shipments. Also, the important feedback from the employees is positive, declaring much easier focusing on working tasks and much safer environment.

The implementation of pick by voice technology is not an optimal solution for every warehouse. Due to high investment costs, the process analysis and continuous day to day process observations, with the focus to change if necessary, is a starting solution. When processes are defined as optimal, according to certain criteria, a technology such as pick by voice can be implemented which will satisfy further continuous improvement.

\section{REFERENCES}

[1] Groose, E. H., Glock, C. H., \& Neumann, P. W. (2015) Human Factors in Order Picking System Design: A Content Analysis. IFAC-PapersOnLine. https://doi.org/10.1016/j.ifacol.2015.06.101

[2] Battini, D., Calzavara, M., Persona, A., \& Sgarbossa, F. (2015). Linking Human Availability and Ergonomics Parameters in Order-Picking Process. IFAC-PapersOnLine. https://doi.org/10.1016/j.ifacol.2015.06.105

[3] Miller, A. (2004). Order Picking for the 21st Century, Voice vs. Scanning Technology. A white paper by Aaron Miller. http://milestechinc.com/pdf/Voice-vsScanning.pdf. (September 2016.) 
[4] Supply Chain Digest Thought Leadership. The 10 Keys to Voice Technology Deployment Success in Distribution Centers, 2013.

[5] Đukić, G., Česnik, V., \& Opetuk, T. (2010). Order-picking Methods and Technologies for Greener Warehousing. Strojarstvo 52(1), 23-31.

[6] Bartholdi, J. J. \& Hackman, S. T. (2011). Warehouse and Distribution Science. The Supply Chain and Logistics Institute, School of Industrial and Systems Engineering, Georgia Institute of Technology, Atlanta, 23-32.

[7] Mendes, P. (2011). Demand Driven Supply Chain: A Structured and Practical Roadmap to Increase Profitability. Springer Berlin Heidelberg. https://doi.org/10.1007/978-3-642-19992-9

[8] Zhang, Y. (2016). Correlated Storage Assignment Strategy to reduce Travel Distance in Order Picking. IFACPapersOnLine, 49(2), 30-35. https://doi.org/10.1016/j.jfacol.2016.03.006.

[9] Rakesh, V. \& Adil, G. K. (2015), Layout Optimization of a Three Dimensional Order Picking Warehouse. IFACPapersOnLine, 48(3), 1155-1160. https://doi.org/10.1016/j.ifacol.2015.06.240.

[10] Frazelle, E. H. (1996). World-Class Warehousing and Material Handling. GA: Logistics Resources International, Atlanta.

[11] Richards, G. (2014). Warehouse Management: A Complete Guide to Improving Efficiency and Minimizing Costs in the Modern Warehouse. Second Edition, New Delhi, Kogan Page Ltd.

[12] Intermec IP Corporation. Optimizing Your Warehouse with Voice. http://www.vocollectvoice.com/optimizing-yourwarehouse-with-voice (October 2016)

[13] Cecere, L. (2013). The Power of Voice. Supply Chain Insights LLC.

[14] Flanders, S. (2002). Voice Directed Picking - A Technology that is ready for Prime Time. Warehouse management Consultatns.

[15] Bourlakis, M., Vlachos, I., \& Zeimpekis, V. (2011). Intelligent Agrifood Chains and Networks, Blackwell Publishing Ltd. https://doi.org/10.1002/9781444339895

\section{Contact information:}

Dujmešić NIKOLA, mag. ing. traff.

University of Zagreb,

Faculty of Transport and Traffic Sciences,

Vukelićeva 4, 10000 Zagreb, Republic of Croatia

E-mail: nikoladujme@gmail.com

Bajor IVONA, PhD

University of Zagreb,

Faculty of Transport and Traffic Sciences,

Vukelićeva 4, 10000 Zagreb, Republic of Croatia

E-mail: ibajor@fpz.hr

Rožić TOMISLAV, PhD

University of Zagreb,

Faculty of Transport and Traffic Sciences,

Vukelićeva 4, 10000 Zagreb, Republic of Croatia

E-mail: trozic@fpz.hr 